\title{
Implementation of an energy management system in a mining and metallurgical enterprise complex as an effective way of ensuring its sustainable development
}

\author{
S. V. Fedorova ${ }^{1}$, A. N. Shemetov ${ }^{1}$, A. L. Chulynin ${ }^{1}$ \\ \& I. A. Shestakova ${ }^{2}$ \\ ${ }^{1}$ Technical University of UMMC, Russia \\ ${ }^{2}$ Ural Federal University, Russia
}

\begin{abstract}
The Ural Mining and Metallurgical Company (UMMC) is one of the major vertically integrated companies in Russia that embrace about 50 enterprises of mining, metallurgical and fabricating complexes, automotive, cable and construction industries and agriculture.

Many enterprises are energy intensive. The share of the energy resources cost in production is over $10 \%$. Annual expenses of enterprises for energy resources make up tens of billions of rubles.

Therefore, an energy management system (EnMS) is one of the key tools ensuring the future growth of the company and its sustainable development.

The authors carried out an analysis of the EnMS implementation results achieved by 9 plants of the group within the project of the United Nations Industrial Development Organization (UNIDO) between 2014 and 2016.

Boundaries of the multiple regression method were defined to create management models for the enterprises of the mining and metallurgical complex.

It was substantiated to use the evolutionary approach to increase accuracy of the enterprise's energy efficiency management models.

Analysis and assessment of evolutionary processes in power engineering enterprises (ontogenesis and succession) at every step of the EnMS (plan-docheck-act) will provide an opportunity to select the optimum combination of methods for establishing an energy management model: a technocoenosis
\end{abstract}


approach, regression analysis, fuzzy sets, artificial neural networks and a support vector machine.

The precise models of the energy efficiency management of enterprises will determine the vector of their sustainable development.

Keywords: energy management system, energy efficiency, evolutionary processes, models, mining and metallurgical complex.

\section{Introduction}

According to the International Organization for Standardization (ISO), as of 2014 6778 organizations in the world were certified for ISO 50001:2011. Annually, this number is increased by about 2100 companies [1].

At present, the developed countries employ proved techniques for the implementation of an energy management system at enterprises based on stable indicative data of development of power engineering and economy for years. For example, in the USA the price of $1 \mathrm{kWh}$ for the final consumer in terms of prices adjusted for inflation is 8 cents (in terms of the prices of 2005) remaining unchanged for over 40 years and the energy strategy of the USA expects an electric energy value increase within the inflation rate in the next 20 years [2].

In Russia, due to a high share of power-intensive industries in the economy structure and continuous growth of tariffs for electric energy, one should consider the technique for EnMS implementation at a specific enterprise as a dynamically updated tool to ensure continuous improvement of energy efficiency.

For companies of the mining and metallurgical complex, arrangement of the energy management system by means of enhanced energy efficiency is characterized by multiplicative effect, which significantly contributes to an increase of competitiveness and sustainable development [3].

This is proved by the results of UMMC and UNIDO project on implementation of EnMS (2014-2016).

UNIDO is the specialized agency of the United Nations that promotes industrial development for poverty reduction, inclusive globalization and environmental sustainability.

The companies participating in the project used UNIDO techniques as a basic one at the initial stage of the project.

To obtain more precise energy resources management models, a basic technique should be improved, considering specific conditions.

The actual difference in culture and arrangement of the production process and a number of contradictions complicate the implementation of EnMS by Russian enterprises, which means that one should pay more attention to the tailoring, taking into account both the characteristics of a specific enterprise and national features [4].

The authors analyzed the developed energy efficiency planning models at the companies, which participated in the project.

They found the limits of implementation of a multiple linear regression method being the key one in the UNIDO technique for analysis of energy consumption and construction of the model. 
They offered an algorithm of selection of the correct mathematical methods for construction of energy efficiency management models in the EnMS.

\section{The practice of introducing an energy management system at the enterprises of a mining and metallurgical complex}

The idea of systematic management of energy resources is to implement an energy management system based on international standard ISO 50001 at the enterprise (fig. 1).

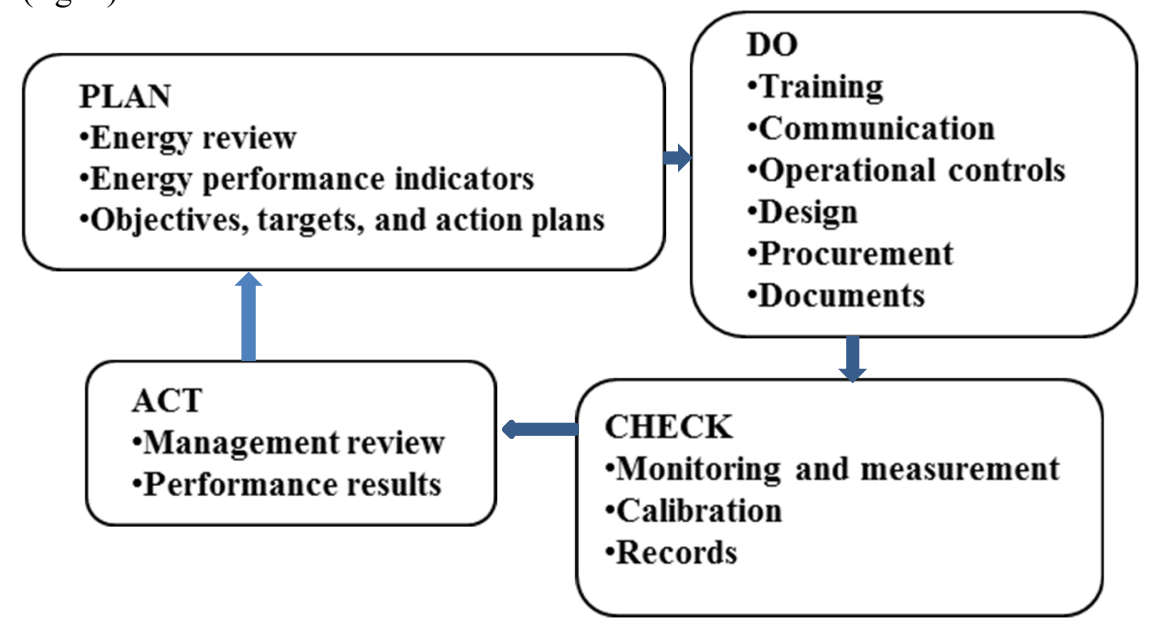

Figure 1: The idea of EnMS at the enterprise.

In the records of the 7th Clean Energy Ministerial that took place in June 2016 in San Francisco, one can find out that the studies conducted worldwide for more than 12,000 companies that implemented ISO 50001 Energy Management System, showed steady improvement in energy performance by $10 \%$ or more.

The UNIDO methodology is the decomposition of the international standard for real production environments and complements it by a system of trainings for working groups of the enterprises.

Through this approach, the energy management system embraces all aspects of the enterprise activities and helps the managers and engineers of the company to make operational management decisions aimed at the minimal consumption of necessary amount of fuel and energy resources (FER) and maximum efficiency, based on the analytical information.

According to UNIDO, the majority of enterprises that have introduced the energy management system annually reduce energy intensity by $2-3 \%$, and the companies that only started to implement an energy management system, can save $10-20 \%$ during the first two years [5].

That is why, initially, it is necessary to determine at what stage of evolutionary process the enterprise currently is in terms of the implementation of energy saving measures to assess the results correctly $[6,7]$. 
If the company is in the process of ontogenesis, the mechanism of energy efficiency management lies within implementing the best practices in energy supply systems, energy transportation and energy consumption, as well as management methods that do not require significant investments, the result of which manifests itself in a short time.

At a particular moment, energy saving measures that lead to the reduction of energy consumption at the initial stage can possibly run their course; further development of efficiency increasing is possible by a "revolutionary" way through the succession. Succession is followed by technological changes, using new energy sources and the introduction of "smart greed". It usually requires large investments.

After innovations, technocoenosis enterprise moves again to the pioneering development stage (ontogenesis) [8-11].

Therefore, energy efficiency management at enterprises is achieved by the transition of steady conditions, in other words, evolutionary and evolutionary stages.

It is proved by the results of EnMS implementation (represented in Figure 2), in the form of a diagram of conformity with ISO 50001 at 9 enterprises of the mining and metallurgical complex, which are involved in the UNIDO project.

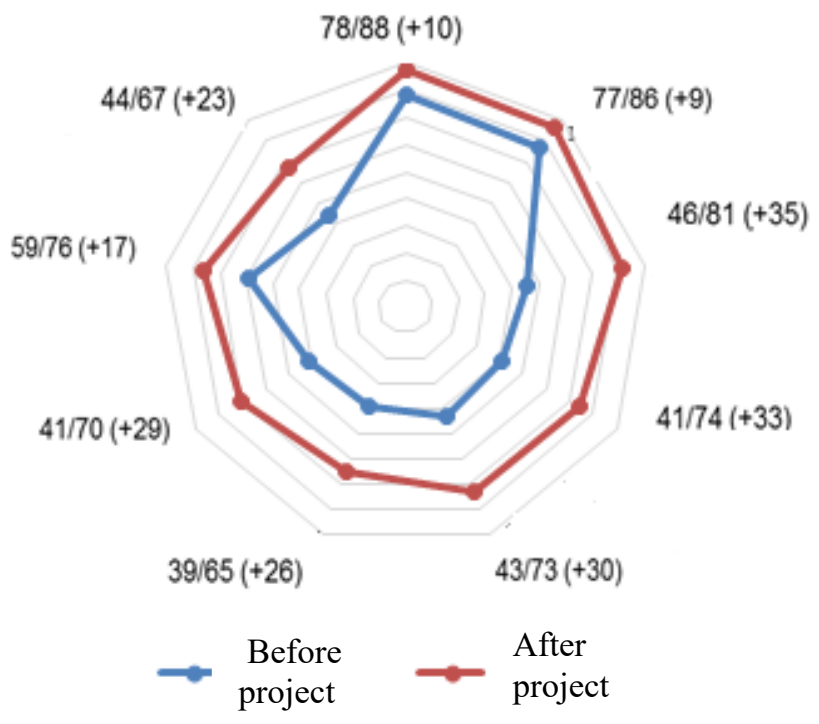

Figure 2: EnMS conformity factors to ISO 50001 at mining and metallurgical enterprises.

At the start of the project, the maximum conformity factor was 78 and the minimum -41 .

The energy objective is the same for all enterprises, namely energy consumption reduction by $3 \%$. Considering that the enterprises were at different 
evolutionary stages of energy efficiency improvement, conformity factor increments differ enormously.

The maximum conformity factor increment 35 was achieved at the mining company. In 2015 alone, the first project year, 20.9 million $\mathrm{kWh}$ of electric energy was saved, amounting to 44 million rubles.

Three linear multiple regression models for SEUs were constructed for evaluation and planning of energy consumption by this company: mining and conveyor equipment $\left(R^{2}=0.646\right)$, hydraulic excavation equipment $\left(R^{2}=0.964\right)$, beneficiation plant $\left(\mathrm{R}^{2}=0.912\right)$.

Reduction in electric energy consumption (with no output reduction) can be explained firstly by constant improvement of energy efficiency and implementation of energy saving program.

During EnMS implementation, costless and low-cost actions have prevailed. The most effective actions are as follows:

- Hydraulic excavation equipment: pressure drop in water supply pipeline up to $19 \mathrm{~atm}$.

- Beneficiation plant: installation of variable-frequency electric drive at the second flow crusher; optimization of crushers operation due to load transfer between the first and the second process flows.

- Mining and excavation equipment: rated load of energy efficient excavators.

Evolutionary process corresponds with ontogenesis.

Low model validity factor for electric energy to be assessed and planned by mining and handling equipment is due to no verified database on production output (data was manually inserted) and no automated technical energy metering system.

To build a more accurate energy management model as the most significant energy resource in case of data uncertainty the alternative methods shall be considered: technocoenosis approach, nonlinear regression analysis, fuzzy sets, artificial neural networks, support vector machine [7-10, 12-15].

\section{Analysis of mathematical methods used in building an energy efficiency management model}

The authors analyzed built energy efficiency management models of the enterprises during the project and potential causes of incorrectness of linear-type correlation model:

$$
Y_{x}=\beta_{0}+\beta_{1} x_{1}+\ldots+\beta_{k} x_{k}+\varepsilon
$$

- When selecting factors, the model included factors nonlinearly related to effective attribute (e.g. target energy consumption savings);

- Correlation model included interrelating factors (with bivariate correlation factor $>0.85$ );

- Insufficient sample scope (information collected within one calendar year, i.e. $n=12$ months);

- Source data is non-uniform (variation factor calculated per each factor, above $33 \%$ );

- Source data does not correspond with normal distribution law; 
- Factors significantly affecting resultative characteristic value are not considered.

If exposures are nonlinearly related to a resultative indicator, nonlinear models can be used: power, exponential, logarithmical, etc.

The authors proposed an algorithm of multiple correlation analysis whereas boundaries of a linear regression method are determined (fig. 3).

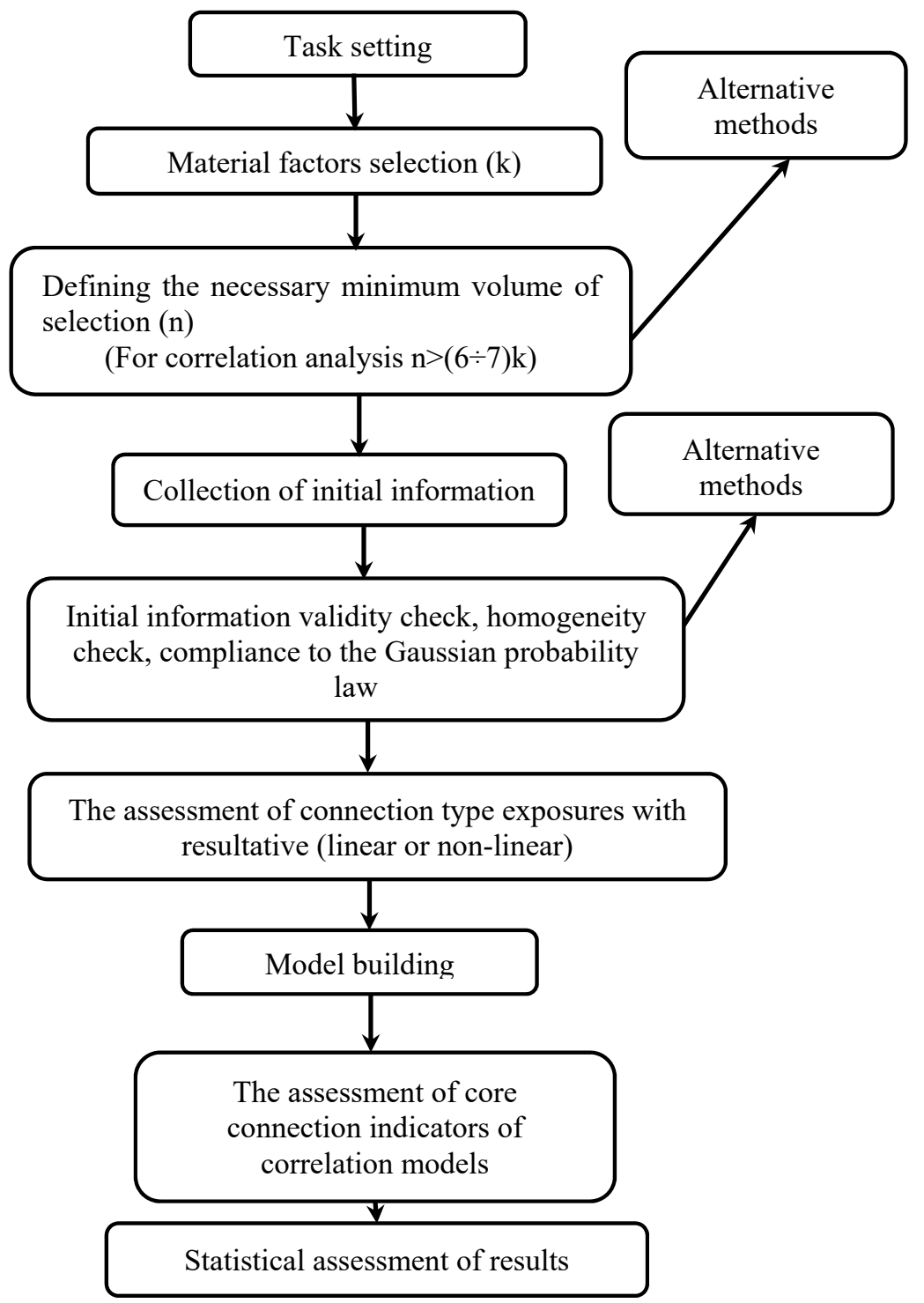

Figure 3: The algorithm of multifactor correlation analysis. 
In the case of decision-making under uncertainty, it is reasonable to use mathematical tools technique of fuzzy sets.

This is of particular relevance for energy intensive enterprises of mining and metallurgical complex working conditions of which are specified by interrelating and often probable set and fuzzy factors.

In theories of automatic controls, in order to solve the following tasks, the mathematical tool of fuzzy logic is widely used; it allows us to describe the degree of data uncertainty in the form of generalized membership function [12-14].

The authors developed an algorithm of method choice for projecting the models of energy resources management of enterprise depending on the type of specific data that defines energy consumption (fig. 4).

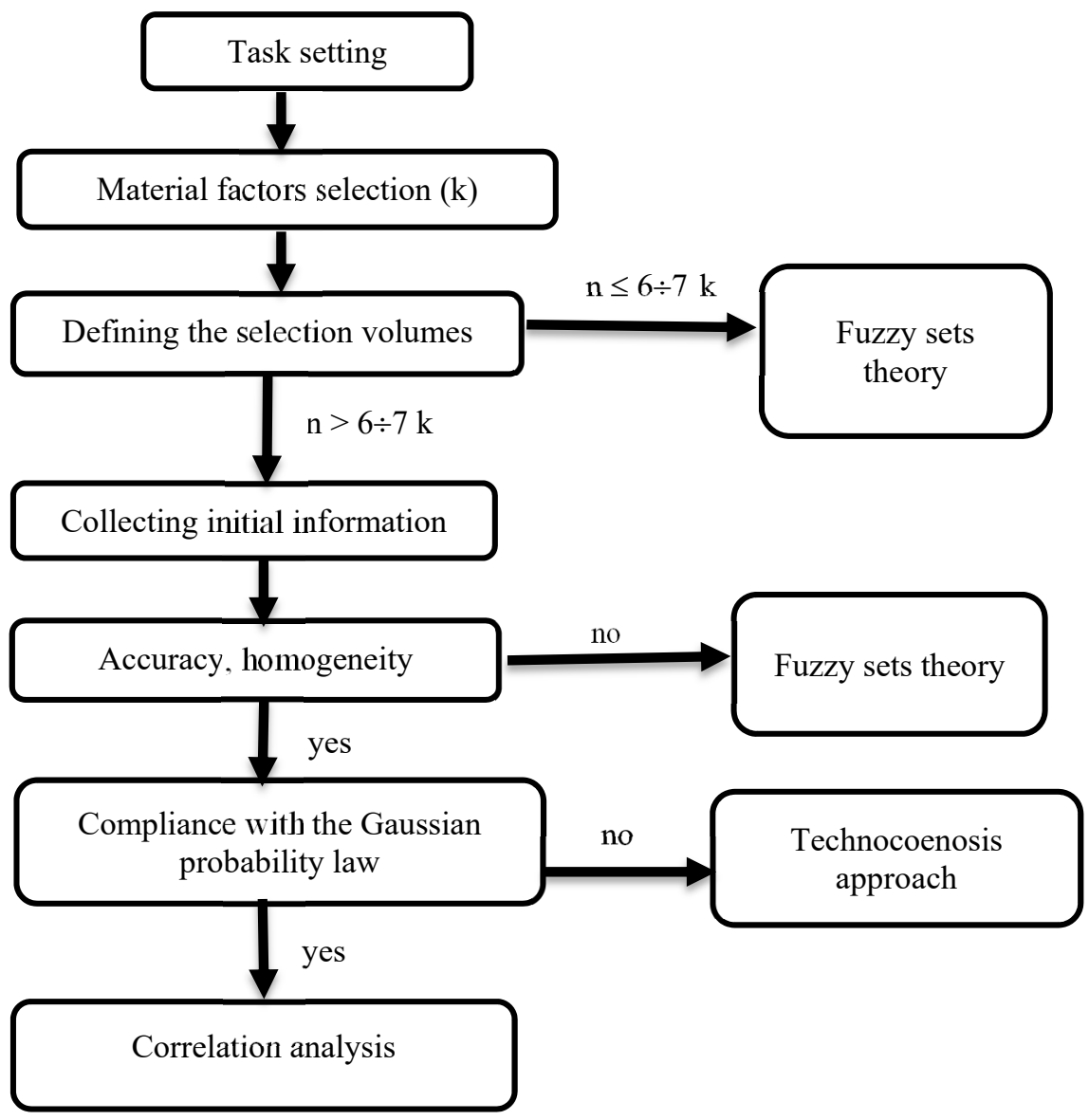

Figure 4: Choice algorithm of enterprise's energy resources management. 
If the enterprise's analyzed data doesn't meet the Gaussian probability law, in other words it's non-Gaussian system with weak internal connections, it is wise to use the approach of technocoenosis, considering the enterprise as a technocenosis, which forms in conditions of limited resources [10].

\section{Conclusion}

The EnMS implementation method on the particular enterprise should be considered as a dynamic renewable tool, able to make a constant energy efficiency improvement with regard to the evolution processes.

The precision of energy efficiency model building defines with the analysis of formed databases and selection of correct mathematic method.

The implementation of constant energy efficiency improvement within the framework of EnMS on enterprise leads to its sustainable development.

\section{References}

[1] The ISO Survey of Management System Standard Certifications 2015 Executive Summary, http://www.iso.org/iso/home/standards/certification /iso-survey.htm?certificate $=$ ISO $\% 2050001 \&$ countrycode=\#standardpick

[2] Grachev, I.D., Nekrasov, S.A. Potential contribution of the consumer to enhancing efficiency of electric power industry. Industrial power engineering, pp. 2-8, № 42016.

[3] 17 indicators of sustainable development: framework and methodologies, UN Commission on Sustainable Development, New York, 2001.

[4] Stepanova, M.V. Energy management in the industry: Russian specifics. Energosovet, pp. 61-64, № 3 (45) 2016.

[5] Konev, A.V. Energy Management - Instrument for Energy Efficiency Improvement and Cost Reduction in Power Sector, Industry and Residential and Utilities Complex. Energy Saving, p. 16, № 52016.

[6] Fedorova, S.V. Evolutionary approach to the management of municipalities' energy efficiency. Innovations and Investments, pp. 207211, № 32014.

[7] Fedorova, S.V., Khudyakov, P.Yu., Melkozerov, N.A., Firsova, D.A. From forecasting methodology of mono-towns' electric energy consumption to its sustainable development. Fifth International Conference on Energy and Sustainability, ISSN 1743-3541 (on-line): Putrajaya, Malaysia, Vol. 186. WIT Transactions on Ecology and the Environment, pp. 206-217, 16-18 December 2014.

[8] Fedorova, S.V. The evolutionary nature of technocoenosis change on example of mono-towns' energy efficiency management. Philosophy. Tolerance. Globalization. The East and the West-Dialogue of Outlooks. Theses of reports VII Russian philosophical congress: Ufa, Volume III, p. 302, on October 6-10 2015. 
[9] Fufaev, V.V. Cenological definition of parameters of electric energy consumption, reliability, installation and repair of region enterprises electric equipment. Moscow: the Center of System Researches, 2000.

[10] Kudrin, B.I. Coenology. Technetics. Electrical/Electronic resource: http://www.kudrinbi.ru.

[11] Fedorova, S.V., Khudyakov, P. Yu. Structural and topological analysis of electric energy consumption of municipalities as the basis for the development of the regional energy efficiency strategy. Proc. of the 1st Int. Scientific Conf. Energy Production and Management in the 21st Century: Yekaterinburg, Russia, Vol.1 WIT Transactions on Ecology and The Environment, Vol. 190, Energy Quest pp. 407-417, on April, 23rd-25th 2014.

[12] Wayne, G.H. Possibility Theory and Fuzzy Sets: Theory of Applications to Energy and Environmental Policy Analysis. The J. Energy and Development, pp. 47-64, v. 17 № 11991.

[13] Methods for Planning under Uncertainty. Towards Flexibility in Power System Development, Van Geert E., Glende I., Halberg N. et al. Electra, pp. 143-163, № 1611995.

[14] Haykin, S. Neural networks: a complete course. Moscow: OOO "I.D. Williams", 2006.

[15] Fufaev, V.V. Structural and topological self-organizing of technical coenosises electric energy consumption S-distributions on examples of the region organizations, the branch enterprises and Russian regions. Coenological researches interdisciplinary. Release 43. Coenological researches. - M: Technetics, pp. 14-26 2010.

[16] Support Vector Machines. Machine learning, http://www.statsoft.ru/home/ textbook/modules/stmachlearn.html. 